\title{
Theoretical Study on Pt Particle Adsorbate Bonding: Influence of Support Ionicity and Implications for Catalysis
}

\author{
Michiel K. Oudenhuijzen, ${ }^{\dagger} \sharp$ Jeroen A. van Bokhoven, ${ }^{\S}$ David E. Ramaker," and \\ Diederik C. Koningsberger*,† \\ Department of Inorganic Chemistry and Catalysis, Debye Institute, Utrecht University, P.O. Box 80083, \\ 3508 TB Utrecht, The Netherlands. Chemistry Department, George Washington University, \\ Washington, D.C. 20052
}

Received: June 28, 2004; In Final Form: September 16, 2004

\begin{abstract}
The influence of the support ionicity on the adsorption of $\mathrm{H}, \mathrm{CH}_{x}(x=2,3)$, and $\mathrm{O}$ on supported Pt particles is investigated using density functional theory (DFT). The DFT calculations reveal that the importance of the $6 \mathrm{~s}, \mathrm{p}$ states for the $\mathrm{Pt}$ adsorbate bonding increases in the order $\mathrm{Pt}-\mathrm{O}<\mathrm{Pt}-\mathrm{CH}_{2}<\mathrm{Pt}-\mathrm{CH}_{3}<\mathrm{Pt}-\mathrm{H}$. Both the $\mathrm{Pt}-\mathrm{H}$ and $\mathrm{Pt}-\mathrm{O}$ bond strengths are strongly affected by changes in the support ionicity whereas the difference for the $\mathrm{Pt}-\mathrm{CH}_{x}$ bond strength is much smaller. The $\mathrm{Pt}-\mathrm{H}$ bond strength is higher for ionic supports, whereas the $\mathrm{Pt}-\mathrm{O}$ bond strength is higher for acidic or more covalent supports. These bond strength changes occur because the support ionicity has a large impact on both the Pt 6s,p and 5d states. On ionic supports with electron rich oxygen atoms, the 6s,p states are pushed toward the surface of a metal cluster where it can participate in $\mathrm{H}$ bonding, whereas on supports with electron poor oxygen atoms (existing in acidic supports or for supports with more covalent cations) the $6 \mathrm{~s}, \mathrm{p}$ states are attracted toward the metal-support interface. The Pt 5d states shift to lower binding energy (lower ionization potential) on ionic supports, where it bonds less effectively with the $\mathrm{O}$ adsorbate. These findings indicate that the hydrogen and oxygen coverage on $\mathrm{Pt}$ particles are strongly determined by the ionicity and acid/base properties of the support and therefore may be the most important for producing changes in the reactivity of $\mathrm{Pt}$ wit support ionicity in various hydrogenolysis, hydrogenation, and oxidation reactions.
\end{abstract}

\section{Introduction}

Supported noble metal catalysts are widely used in commercially important reactions, including hydrogenation, naphtha reforming, and isomerization reactions, and in electrocatalysis redox reactions involving $\mathrm{O}_{2}$ and $\mathrm{H}_{2}$ such as that taking place in a fuel cell. ${ }^{1}$ Dalla Batta and Boudart made the first report of enhanced reaction rates with specific supports. ${ }^{2}$ Since then, it has been well established that the nature of the support influences the rate of hydrogenation and hydrogenolysis reactions on catalytically active metal particles. ${ }^{3-10}$ For example, in the conversion of neopentane $\left(\mathrm{C}-\left(\mathrm{CH}_{3}\right)_{4}\right)$, it has been observed that the rate of hydrogenolysis is several orders of magnitude higher when Pt particles are supported on an acidic support compared to a basic support. In addition, the inhibition by hydrogen of the hydrogenolysis of alkanes is much stronger for basic supports: the order in $\mathrm{H}_{2}$ ranges from -2.5 (basic support) to -1.5 (acidic). ${ }^{10-13}$

Although the effect of the support on the catalytic properties of the supported metal particles has been well established, at least for reactions involving $\mathrm{H}$, the nature of this metal-support interaction has been the subject of much debate. Explanations have involved the formation of metal-proton adducts on

\footnotetext{
* Corresponding author. Tel: +31302573400. E-mail: d.c.koningsberger@chem.uu.nl.

†trecht University.

$\div$ Present address: GE Plastic Europe, P.O. Box 117, 4600 AC Bergen op Zoom, The Netherlands.

$\S$ Present address: Lab. für Technische Chemie, ETH Hoenggerberg/ HCI E115, CH-8093 Zürich, Schweiz.

"George Washington University.
}

Brønsted acidic supports, 5,14 electron transfer between support and particle, $, 15,16$ the polarization of the metal particle by nearby cations, ${ }^{17}$ and a change in the ionization potential of the metal, due to a shift in the d-band density of states. ${ }^{8,9,18,19}$

Work by our group revealed that the nature of the metal support interaction involves a change in the electronic properties of the metal cluster, induced by and correlated to the electron richness of the support oxygen atoms. ${ }^{8,9,18}$ This oxygen electron richness is determined primarily by the ionic character of the cations in the oxide support; with electron rich oxygens existing in basic supports with alkaline cations, and electron poor oxygens existing in acidic supports with protons or other more covalent cations. X-ray absorption fine structure experiments $\left(\mathrm{L}_{2}\right.$ and $\mathrm{L}_{3}$ near edge structure and Atomic XAFS) and density functional theory (DFT) calculations on supported Pt clusters revealed that the support influences the electronic properties of a metal particle in at least three separate ways: (i) the complete Pt density of states (DOS) shifts to higher energy (lower binding energy) with increasing electron richness of the support oxygen atoms, ${ }^{8,9}$ (ii) the location of the $6 \mathrm{~s}, \mathrm{p}$ bonding orbital (IBO: interstitial bonding orbital ${ }^{20}$ ) moves from the metal-support interface to the surface of the Pt particles with increasing electron richness of the support oxygen atoms, ${ }^{18}$ and (iii) the insulator to metal transition with increasing cluster size is shifted to lower particle sizes on basic supports. ${ }^{21}$

The change in electronic structure of the Pt particles induced by the support ionicity and acid/base properties will affect the bonding of adsorbates on the Pt surface; however, it is not clear which of the above-mentioned changes in electronic structure play a dominant role in the bonding of adsorbates. Recent 
theoretical calculations reported in the literature are mostly performed on slabs with periodic boundary conditions, or on relatively small clusters chosen to model flat $\mathrm{Pt}(111)$ surfaces (see review of these calculations in ref 23). In contrast, our group $^{10,22,23}$ performed density functional calculations using the ADF code on a model $\mathrm{Pt}_{4} /\left(\mathrm{X}_{2} \mathrm{O}_{3}\right)$ cluster, where the $\mathrm{X}_{2} \mathrm{O}$ groups mimic the support $(X=F$, covalent; $X=H$, neutral; $X=\mathrm{Na}$, ionic) to investigate the influence of the electron richness of the support oxygens on the electronic structure of small $\mathrm{Pt}$ particles. The calculations show that the $\mathrm{Pt}-\mathrm{H}$ bond strength is higher for Pt particles on ionic supports. The atop position for hydrogen adsorbed on $\mathrm{Pt}$ is preferred only at very low $\mathrm{H}$ coverage and low Pt coordination (cluster corners). ${ }^{22,24}$ Increasing the hydrogen coverage forces this atop $\mathrm{H}$ to move to an $n$-fold site, to reduce lateral interactions. The calculations show that the adsorption energy in the $n$-fold sites existing at high hydrogen coverage increases on the ionic (basic) supports, implying that the fraction of strongly bonded hydrogen is larger in ionic (basic) supports. This knowledge together with information on the dominant hydrogen absorption sites (atop or $n$-fold) obtained from $\mathrm{Pt} \mathrm{L}_{3} \mathrm{X}$-ray absorption near edge data (XANES), was used to analyze previously reported neopentane hydrogenolysis kinetic data. ${ }^{10}$ The results from that analysis provided a basic understanding of the metal-support interaction for hydrogenolysis reactions of alkanes catalyzed by Pt particles on supports with different ionicity and acid/base properties. At a fundamental level, the support alters the equilibrium thermodynamic coverage of $\mathrm{H}$. This influences the bonding of the neopentane to the surface, thereby changing the "apparent" activation energy for the reaction.

The effects of the support on the adsorption of oxygen are in the opposite direction to that found for hydrogen. ${ }^{23}$ The $\mathrm{Pt}-\mathrm{O}$ bond strength is higher for Pt on supports with a lower electron richness (covalent or acidic). The oxygen adsorption site also depends on the support properties. Oxygen is adsorbed in a 3-fold hep and/or subsurface Pt site on supports with low electron richness of the support oxygen, whereas on ionic supports the 2-fold (bridge) sites are preferred. ${ }^{25}$ These bond strength changes could be related to the increase in energy position (higher binding energy) of the $\mathrm{Pt} 5 \mathrm{~d}$ orbitals with covalent or acidic supports. This shift to higher binding energy leads to a more covalent character (stronger bond) in the $\mathrm{Pt}-\mathrm{O}$ interaction.

It remains unclear how the bonding of hydrocarbons is affected by changes in the electronic properties of supported metal clusters. It seems obvious that the changes in the DOS within a supported $\mathrm{Pt}$ particle as a function of the support ionicity and acid/base properties will affect the chemisorption of $\mathrm{CH}_{x}$ and other hydrocarbons on the surface as well, but will they track in the direction of $\mathrm{H}$ or $\mathrm{O}$ bonding. The reported data in the literature regarding the adsorption of $\mathrm{CH}_{x}$ on metals mainly focus on $\mathrm{Pt}(111)$ flat surfaces. ${ }^{20,26-28}$ However, the flat surfaces areas are very small in the case of highly dispersed metal particles, because these particles mainly consist of edge and step sites. Theoretical work has suggested that the metal $d$ states are more important for chemisorbed $\mathrm{CH}_{x}$ fragments. ${ }^{20,26-28}$

In this paper the influence of the support ionicity on the chemisorption of $\mathrm{O}, \mathrm{CH}_{x}$, and $\mathrm{H}$ is compared with the help of density functional calculations using the ADF package. ${ }^{29} \mathrm{CH}_{3}$ and $\mathrm{CH}_{2}$ adsorbates are modeled on a $\mathrm{Pt}_{4} /\left(\mathrm{X}_{2} \mathrm{O}\right)_{3}$ cluster (see Figure 1) exactly similar to our previously reported calculations on $\mathrm{H}$ and $\mathrm{O}$. Because it is computationally expensive (although possible) to simulate a complete support matrix, the $\mathrm{Pt}_{4}$ clusters in this work are placed on three $\mathrm{X}_{2} \mathrm{O}$ molecules to mimic the

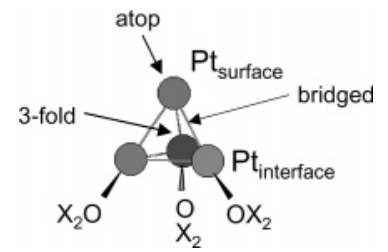

Figure 1. $\mathrm{Pt}_{4} / \mathrm{X}_{2} \mathrm{O}$ cluster with three different adsorption sites.

support, where the $\mathrm{O}$ atoms mimic similar oxygen atoms of the support. The change in $\mathrm{O}-\mathrm{Si}(\mathrm{Al})$ ionic character, which alters the $\mathrm{O}$ support atoms in "real" supports from being electron rich (ionic, basic supports) to electron poor (covalent, acidic supports) is simulated in the cluster by varying the nature of the $\mathrm{X}$ atom. $\mathrm{F}_{2} \mathrm{O}$ ( $\mathrm{F}$ is very electronegative, therefore giving an electron poor oxygen atom) represents an acidic support whereas $\mathrm{Na}_{2} \mathrm{O}$ ( $\mathrm{Na}$ is less electronegative than oxygen, thus giving electron rich oxygen atoms) mimics a basic support. It was shown earlier ${ }^{10,22,23}$ that this simple model of cluster plus support reproduces the electronic structure of the Pt clusters and the changes with support ionicity quite well. However, with six $\mathrm{X}$ atoms near the $\mathrm{Pt}_{4}$, the $\mathrm{Pt}_{4} /\left(\mathrm{X}_{2} \mathrm{O}\right)_{3}$ cluster perhaps models extremely acidic and basic supports and may not be modeling all aspects of the support accurately; such as the local field in an ionic oxide. The theoretical results will show that the support ionicity has a very strong influence on the adsorption of $\mathrm{H}$ and $\mathrm{O}$, whereas the effect of the support on $\mathrm{CH}_{3}$ and $\mathrm{CH}_{2}$ adsorption is much smaller. The shift in location of the IBO within the Pt particle and the position in energy of the $5 \mathrm{~d}$ orbitals induced by the support ionicity are the most critical factors in altering the $\mathrm{Pt}-\mathrm{H}$ and $\mathrm{Pt}-\mathrm{O}$ adsorption energy, respectively. The implications of these results for catalysis will be discussed.

\section{Computational Methods}

The DFT calculations reported here have been performed using the Amsterdam Density Functional Package ADF. ${ }^{29}$ This package uses the Kohn-Sham approach to the densityfunctional theory. Slater-type orbitals are used to represent the atomic orbitals. All basis sets consist of triple- $\zeta$ quality, extended with two polarization functions. The density functional was calculated using the Vosko-Wilk-Nussair approximation of the local density approximation (LDA), and using the Becke gradient correction ${ }^{30}$ and Perdew correlation term ${ }^{31}$ for the generalized gradient approximation (GGA). To enhance computational efficiency, several atomic core shells of the Pt atoms were frozen up to and including the Pt $4 \mathrm{~d}$ level. Relativistic effects were accounted for using the ZORA approximation. ${ }^{32,33}$ The geometry optimizations that were performed were carried out in the spin-restricted mode including scalar relativistic effects, thereby excluding spin-orbit effects. This level of accuracy has been reported to agree well with experimental data. ${ }^{34}$ The numerical integration precision applied was set to 5.5 significant digits. The applied criteria for the geometry optimization were $1 \times 10^{-3}$ hartree for the changes in energy, $1 \times 10^{-4}$ hartree/ $\AA$ for changes in the energy gradients and 1 $\times 10^{-2} \AA$ for changes in the Cartesian coordinates.

The clusters that were investigated consist of a $\mathrm{Pt}_{4}$ tetrahedron supported by three $\mathrm{X}_{2} \mathrm{O}$ molecules, with $\mathrm{X}=\mathrm{Na}$ or $\mathrm{F}$. The global geometry is shown in Figure 1 . In this small $\mathrm{Pt}_{4}$ cluster all four Pt atoms are at the surface of the cluster; however, only the apical $\mathrm{Pt}$ atom is designated $\mathrm{Pt}_{\text {surface}}$, because in the model cluster this Pt atom is involved with bonding to the adsorbates in all cases. In contrast, the $\mathrm{Pt}$ atoms labeled $\mathrm{Pt}_{\text {interface }}$ are in direct contact with the support, and bond with the asorbate only in the bridged, and fcc adsorbate binding sites. The geometry 
TABLE 1: Heat of Adsorption ( $\left.E_{\text {ads }}\right)$ and Intrinsic Bond Energy $\left(E_{\text {int }}\right)$ for the Adsorption of $\mathrm{H}_{2}$ and $\mathrm{CH}_{n}$ in the Atop, Bridged (br), and 3-Fold Hollow Site (3-f) on $\mathrm{Pt}_{4} / \mathrm{F}_{2} \mathrm{O}$ or $\mathrm{Pt}_{4} / \mathrm{Na}_{2} \mathrm{O}$

\begin{tabular}{cllllll}
\hline & & \multicolumn{2}{c}{$E_{\text {ads }}(\mathrm{kJ} / \mathrm{mol})$} & & \multicolumn{2}{c}{$E_{\text {int }}(\mathrm{kJ} / \mathrm{mol})$} \\
\cline { 3 - 4 } adsorbate & & $\mathrm{Pt}_{4} / \mathrm{F}_{2} \mathrm{O}$ & $\mathrm{Pt}_{4} / \mathrm{Na}_{2} \mathrm{O}$ & & $\mathrm{Pt}_{4} / \mathrm{F}_{2} \mathrm{O}$ & $\mathrm{Pt}_{4} / \mathrm{Na}_{2} \mathrm{O}$ \\
\hline $\mathrm{H}^{a}(22)$ & atop & -106.0 & -175.2 & & -375.8 & -410.4 \\
& br & +105.4 & -14.8 & & -270.1 & -330.2 \\
& 3-f & & unstable $^{b}$ & & \\
$\mathrm{CH}_{3}$ & atop & -59.7 & -110.1 & -303.8 & -319.5 \\
& br & & unstable $^{b}$ & & \\
& 3-f & & unstable $^{b}$ & & \\
$\mathrm{CH}_{2}$ & atop & +1.6 & -86.7 & & -553.4 & -572.5 \\
& br & -49.6 & -105.7 & & -604.6 & -591.5 \\
& 3-f & +23.2 & unstable & & -531.8 & unstable \\
& $\mathrm{O}(23)$ & br & & & -545 & -383
\end{tabular}

${ }^{a}$ The adsorption energy $E_{\text {ads }}$ for $\mathrm{H}_{2}$ is in $\mathrm{kJ} / \mathrm{mol}$ of $\mathrm{H}_{2}$; the intrinsic energy $E_{\text {int }}$ is in $\mathrm{kJ} / \mathrm{mol}$ of $\mathrm{H} .{ }^{b}$ The adsorbed fragment drifted to the most stable position during the geometry optimization.

of the clean $\mathrm{Pt}_{4} / \mathrm{X}_{2} \mathrm{O}$ was optimized within the boundaries of $C_{3 v}$ symmetry. $\mathrm{CH}_{3}$ or $\mathrm{CH}_{2}$ fragments were placed in the atop, bridged or 3 -fold sites (see Figure 1). The $\mathrm{Pt}_{4}$ cluster with adsorbate was allowed to relax its geometry within the limits of $C_{s}$ symmetry; however, the coordinates of the $\mathrm{X}_{2} \mathrm{O}$ molecules were fixed to represent the rigid nature of a real support.

The bond energy is calculated in two ways. The "heat of adsorption", $E_{\text {ads }}$, reflects the decomposition of the gas-phase molecule into fragments followed by adsorption of these fragments onto the Pt cluster. The gas-phase molecule was either $\mathrm{H}_{2}$ or $\mathrm{CH}_{4}$. Thus, $E_{\text {ads }}$ for $\mathrm{H}_{2}$ is calculated by taking the difference in the total energy of $\mathrm{Pt}_{4}-\mathrm{H} / \mathrm{X}_{2} \mathrm{O}$ and $\mathrm{H}_{2}+\mathrm{Pt}_{4} / \mathrm{X}_{2} \mathrm{O}$ :

$$
E_{\mathrm{ads}, \mathrm{H}_{2}}=2 E_{\mathrm{Pt}_{4}-\mathrm{H} / \mathrm{X}_{2} \mathrm{O}}-2 E_{\mathrm{Pt}_{4} / \mathrm{X}_{2} \mathrm{O}}-E_{\mathrm{H}_{2}}
$$

The total energy of a cluster was determined relative to the atomic reference energies according to Baerends et al. ${ }^{35}$ In calculating the adsorption energy of $\mathrm{CH}_{n}$ it was assumed that the hydrogen fragment adsorbs on a clean cluster, and thus the adsorption energy $E_{\text {ads }}$ is given by:

$$
\begin{aligned}
& E_{\text {ads }, \mathrm{CH}_{n}}=E_{\mathrm{Pt}_{4}-\mathrm{CH}_{n} / \mathrm{X}_{2} \mathrm{O}}+(4-n) E_{\mathrm{Pt}_{4}-\mathrm{H} / \mathrm{X}_{2} \mathrm{O}}- \\
&(5-n) E_{\mathrm{Pt}_{4} / \mathrm{X}_{2} \mathrm{O}}-E_{\mathrm{CH}_{4}}
\end{aligned}
$$

The "intrinsic bond energy" reflects the energy required to remove a fragment adsorbed on the $\mathrm{Pt}_{4}$ cluster to the gas phase. It is given for hydrogen bonded on $\mathrm{Pt}_{4}$ by

$$
E_{\text {int, } \mathrm{H}}=E_{\mathrm{Pt}_{4}-\mathrm{H} / \mathrm{X}_{2} \mathrm{O}}-E_{\mathrm{H}}-E_{\mathrm{Pt}_{4} / \mathrm{X}_{2} \mathrm{O}}
$$

and for a $\mathrm{CH}_{n}$ fragment bonded on $\mathrm{Pt}_{4}$ :

$$
E_{\mathrm{int}, \mathrm{CH}_{n}}=E_{\mathrm{Pt}_{4}-\mathrm{CH}_{n} / \mathrm{X}_{2} \mathrm{O}}-E_{\mathrm{CH}_{n}}-E_{\mathrm{Pt}_{4} / \mathrm{X}_{2} \mathrm{O}} \quad\left(\mathrm{CH}_{n} \text { bonding }\right)
$$

\section{Results}

Hydrogen Adsorption. Although the calculations for $\mathrm{H}$ on the model cluster utilized in this work have been reported previously, the heats of adsorption, $E_{\text {ads }}$, and intrinsic bond energies $E_{\text {int }}$ for $\mathrm{Pt}-\mathrm{H}$ are given here in Table 1 . The optimized geometries are given in Figure 2 for completeness. Regardless of the support $\left(\mathrm{Na}_{2} \mathrm{O}\right.$ vs $\left.\mathrm{F}_{2} \mathrm{O}\right)$, when starting in the 3-fold hollow site, the hydrogen drifts to the atop site after geometry optimization. Moreover, a single hydrogen in the atop site is much more stable than in the bridged site (Table 1). Also, $E_{\text {ads }}$
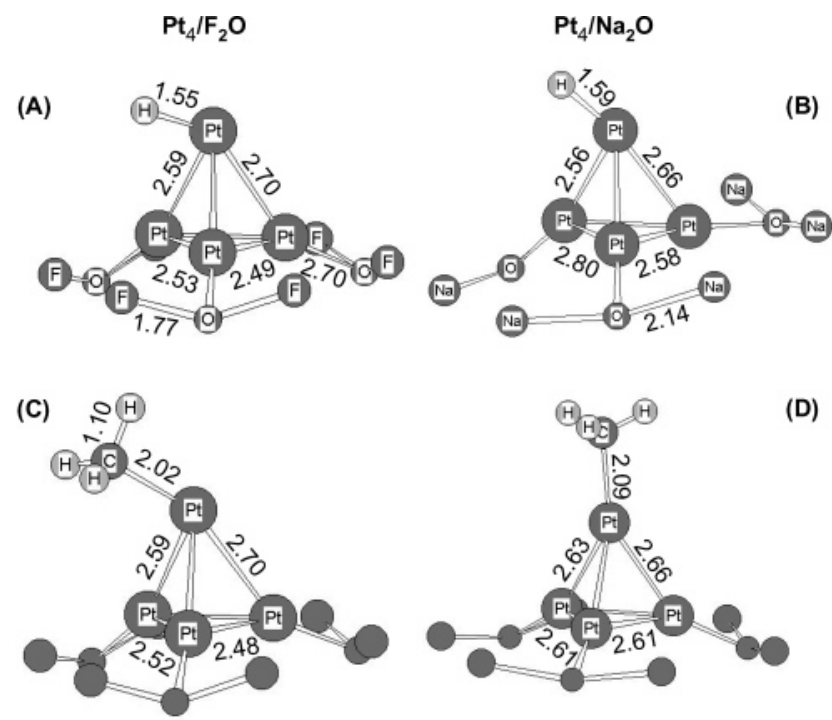

(D)
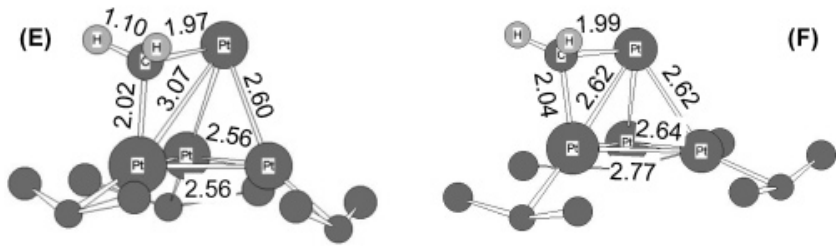

Figure 2. Optimized geometries of a $\mathrm{Pt}_{4}$ cluster. Hydrogen adsorbed in the atop position: (A) $\mathrm{F}_{2} \mathrm{O}$ and (B) $\mathrm{Na}_{2} \mathrm{O}$ support. $\mathrm{CH}_{3}$ adsorbed atop: (C) $\mathrm{F}_{2} \mathrm{O}$ and (D) $\mathrm{Na}_{2} \mathrm{O}$ support. $\mathrm{CH}_{2}$ adsorbed in the bridged position: (E) $\mathrm{F}_{2} \mathrm{O}$ and $(\mathrm{F}) \mathrm{Na}_{2} \mathrm{O}$ support. The $\mathrm{C}-\mathrm{H}$ bond length was not affected by the support, the $\mathrm{Pt}-\mathrm{O}$ and $\mathrm{O}-\mathrm{X}$ bond lengths were unaffected by the adsorbate. The bond lengths are given in $\AA$.

for this single atop $\mathrm{H}$ atom is $70 \mathrm{~kJ} /\left(\mathrm{mol} \mathrm{H}_{2}\right)$ more exothermic for $\mathrm{Pt}_{4} / \mathrm{Na}_{2} \mathrm{O}$ than for $\mathrm{Pt}_{4} / \mathrm{F}_{2} \mathrm{O}$. Analogous to the heat of adsorption, the intrinsic bond strength is increased by $35 \mathrm{~kJ} /$ (mol H) for the basic support.

The hydrogen in the atop site is found to be tilted toward the interface, and this tilt is largest in the case of the $\mathrm{Pt}_{4} / \mathrm{F}_{2} \mathrm{O}$ : compare Figure $2 \mathrm{~A}$ with $\mathrm{B}$. The $\mathrm{Pt}-\mathrm{H}$ bond length is $1.55 \AA$ for adsorption in the atop position on the $\mathrm{Pt}_{4} / \mathrm{F}_{2} \mathrm{O}$ cluster, with $\mathrm{Pt}-\mathrm{Pt}$ bond lengths varying from 2.49 to $2.59 \AA$. For $\mathrm{Pt}_{4} / \mathrm{Na}_{2} \mathrm{O}$, the $\mathrm{Pt}-\mathrm{H}$ bond length is $1.59 \AA$, and the $\mathrm{Pt}-\mathrm{Pt}$ bond lengths range from 2.56 to $2.59 \AA$.

The gross population density of states (GPDOS) for the $\mathrm{H}$ and $\mathrm{Pt}_{\text {surface }}$ atoms for the $\mathrm{Pt}_{4} / \mathrm{F}_{2} \mathrm{O}$ and $\mathrm{Pt}_{4} / \mathrm{Na}_{2} \mathrm{O}$ clusters are shown in Figures 3 and 4, respectively. Several observations can be made: The $\mathrm{H}$ 1s state around $-12 \mathrm{eV}$ is split into multiple peaks, with maxima aligning with peaks in the Pt 6s,p DOS. The Pt 5d band also has significant intensity and overlaps with the maxima in the $\mathrm{H} 1 \mathrm{~s}$ DOS, suggesting that $5 \mathrm{~d}$ also participates in the bonding. Above the Fermi level, the $\mathrm{H} 1 \mathrm{~s}-$ $\mathrm{Pt} 6 \mathrm{~s}, \mathrm{p}$ antibonding state (AS) is clearly visible. Compared with the acidic $\mathrm{F}_{2} \mathrm{O}$ support, the $\mathrm{H} 1 \mathrm{~s}$ also overlaps similarly with the $\mathrm{Pt} 6 \mathrm{~s}, \mathrm{p}$ and $\mathrm{Pt} 5 \mathrm{~d}$ states on the $\mathrm{Na}_{2} \mathrm{O}$ support, but now much more with the Pt $6 \mathrm{p}$. Indeed, the significant increase of $6 \mathrm{~s}, \mathrm{p}$ contribution overlapping with the $\mathrm{H} 1$ s around -4 and $-9 \mathrm{eV}$ appears to be the major difference between the $\mathrm{F}_{2} \mathrm{O}$ and $\mathrm{Na}_{2} \mathrm{O}$ supports. Moreover, there are clearly more Pt 6sp states below the Fermi level in the $\mathrm{Na}_{2} \mathrm{O}$ case.

$\mathbf{C H}_{3}$ Adsorption. The most favorable adsorption site for a single $\mathrm{CH}_{3}$ on the supported $\mathrm{Pt}_{4}$ cluster is the atop position. If $\mathrm{CH}_{3}$ was placed in another adsorption site initially, it drifted to the atop position during the geometry optimization. The optimized geometries for $\mathrm{CH}_{3}$ adsorbed on the $\mathrm{Pt}_{4} / \mathrm{F}_{2} \mathrm{O}$ and $\mathrm{Pt}_{4} /$ 


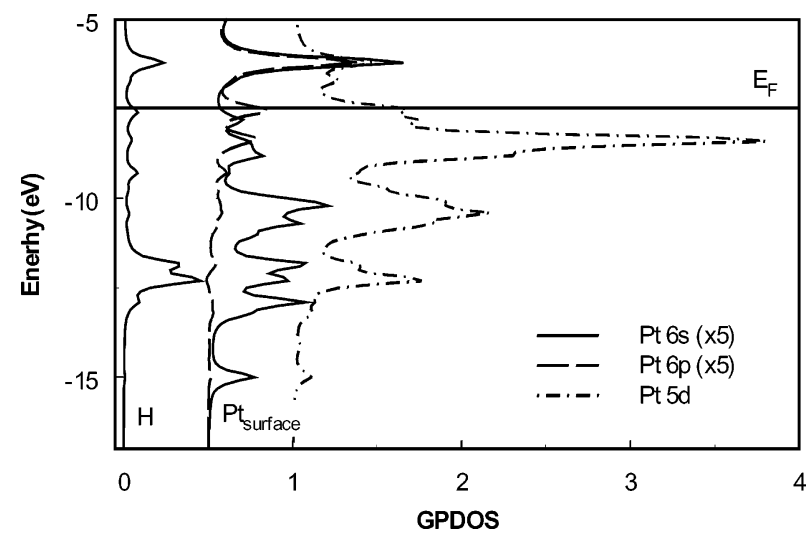

Figure 3. $\mathrm{H} 1 \mathrm{~s}$ GPDOS and the surface Pt atom 5d,6s,p GPDOS for hydrogen adsorbed in the atop position on a $\mathrm{Pt}_{4} / \mathrm{F}_{2} \mathrm{O}$ cluster. The $\mathrm{Pt} 6 \mathrm{~s}$ and $6 \mathrm{p}$ GPDOS is magnified by a factor of $5 . E_{\mathrm{F}}$ is the Fermi level.

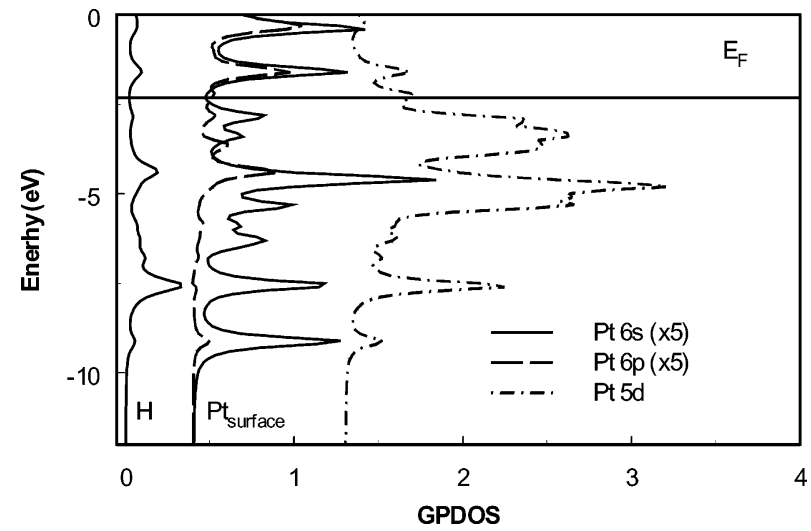

Figure 4. $\mathrm{H} 1 \mathrm{~s}$ GPDOS and the surface Pt atom 5d,6s,p GPDOS for hydrogen adsorbed in the atop position on a $\mathrm{Pt}_{4} / \mathrm{Na}_{2} \mathrm{O}$ cluster. The $\mathrm{Pt}$ $6 \mathrm{~s}$ and $6 \mathrm{p}$ GPDOS is magnified by a factor of $5 . E_{\mathrm{F}}$ is the Fermi level.

$\mathrm{Na}_{2} \mathrm{O}$ cluster are shown in Figure 2C,D. The $\mathrm{Pt}-\mathrm{C}$ bond length for the $\mathrm{Pt}_{4} / \mathrm{F}_{2} \mathrm{O}$ (and $\mathrm{Pt}_{4} / \mathrm{Na}_{2} \mathrm{O}$ ) cluster is $2.02 \AA(2.09 \AA$ ) and the $\mathrm{Pt}-\mathrm{Pt}$ bond lengths range between 2.48 and $2.70 \AA$ ( 2.61 and $2.66 \AA$ ). The $\mathrm{CH}_{3}$ adsorbate is tilted toward the interface with the $\mathrm{F}_{2} \mathrm{O}$ support, but nearly perfectly in the atop geometry for the $\mathrm{Na}_{2} \mathrm{O}$ support.

The intrinsic bond energy $E_{\text {int }}$ for $\mathrm{Pt}-\mathrm{CH}_{3}$ is smaller for the acidic support (Table 1), just as was observed for the $\mathrm{Pt}-\mathrm{H}$ bond; however, the difference is much smaller for $\mathrm{CH}_{3}: 16 \mathrm{~kJ} /$ $\left.(\mathrm{mol} \mathrm{CH})_{3}\right)$ vs $35 \mathrm{~kJ} /(\mathrm{mol} \mathrm{H})$. The heat of adsorption for $\mathrm{CH}_{3}$ is $50 \mathrm{~kJ} / \mathrm{mol}$ smaller in the case of an acidic support compared to a basic support.

The GPDOS for $\mathrm{CH}_{3}$ adsorbed in the atop position on the $\mathrm{Pt}_{4} / \mathrm{F}_{2} \mathrm{O}$ cluster is shown in Figure 5. Because no extra information is obtained from the results for the $\mathrm{Pt}_{4} / \mathrm{Na}_{2} \mathrm{O}$ cluster, these results are omitted. For the $\mathrm{Pt}_{4} / \mathrm{F}_{2} \mathrm{O}$ cluster, the DOS show maxima at approximately $-12 \mathrm{eV}$ for both the $\mathrm{H} 1 \mathrm{~s}$ and $\mathrm{C} 2 \mathrm{~s}, \mathrm{p}$ states. These maxima represent the $\mathrm{C}-\mathrm{H}$ bond involving the $\mathrm{C}$ $2 \mathrm{p}_{z}$ orbital. This $\mathrm{C}-\mathrm{H}$ bonding orbital is degenerate with some Pt $5 \mathrm{~d}$ states, indicating that some mixing between those orbitals occurs. The overlap between the $\mathrm{C} 2 \mathrm{~s}$ and $\mathrm{H} 1 \mathrm{~s}$ orbital is located at lower energy and is not shown in Figure 5. At $\sim-11 \mathrm{eV}$, a second, smaller peak in the C $2 p$ DOS is visible, corresponding to a peak in the $\mathrm{Pt} 6 \mathrm{~s}, \mathrm{p}$ states. The $\mathrm{H} 1 \mathrm{~s}$ shows no intensity at that energy, suggesting that this is primarily the $\mathrm{Pt}-\mathrm{C}$ bond. Therefore the $\mathrm{Pt}-\mathrm{C}$ has significant $6 \mathrm{~s}$ and $5 \mathrm{~d}$ character. Just above the Fermi level another maximum in the $\mathrm{C} 2 \mathrm{p}$ and $\mathrm{Pt}$ $6 s, p$ states is visible, showing the antibonding state.

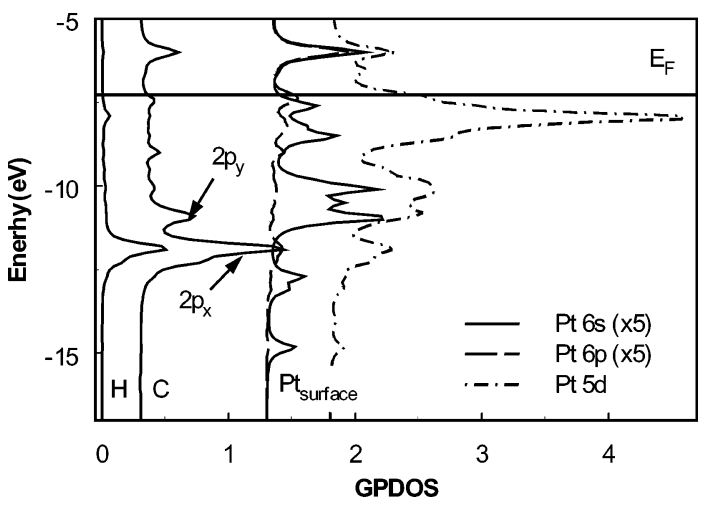

Figure 5. $\mathrm{H}$ 1s GPDOS, $\mathrm{C} 2 \mathrm{~s}, 2 \mathrm{p}$ GPDOS and the surface $\mathrm{Pt}$ atom 5d,6s,p GPDOS for $\mathrm{CH}_{3}$ adsorbed in the atop position on a $\mathrm{Pt}_{4} / \mathrm{F}_{2} \mathrm{O}$ cluster. The Pt $6 \mathrm{~s}$ and $6 \mathrm{p}$ GPDOS is magnified by a factor of $5 . E_{\mathrm{F}}$ is the Fermi level.

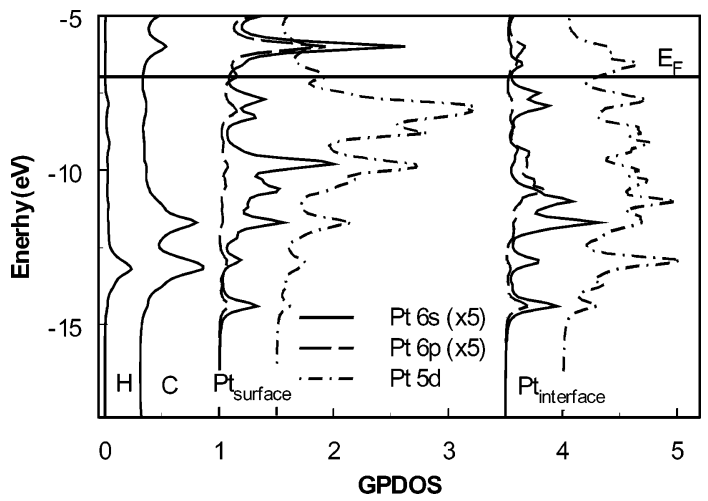

Figure 6. H 1s GPDOS, C 2s,p GPDOS and the surface and interface Pt atom 5d,6s,p GPDOS for $\mathrm{CH}_{2}$ adsorbed in the bridged position on a $\mathrm{Pt}_{4} / \mathrm{F}_{2} \mathrm{O}$ cluster. The $\mathrm{Pt} 6 \mathrm{~s}$ and $6 \mathrm{p}$ GPDOS is magnified by a factor of 5. $E_{\mathrm{F}}$ is the Fermi level.

$\mathbf{C H}_{2}$ Adsorption. The favored adsorption site for the $\mathrm{CH}_{2}$ fragment is the bridged site for both supports. The optimized geometries are shown in Figure 2E,F. The two hydrogen atoms are eclipsed with respect to the two Pt atoms bonded to the carbon. In other words, $\mathrm{CH}_{2}$ shows a tetrahedral coordination together with the two $\mathrm{Pt}$ atoms. The $\mathrm{Pt}_{\text {interface }}-\mathrm{C}$ bond lengths are 2.02 and $2.04 \AA$ and the $\mathrm{Pt}_{\text {surface }}-\mathrm{C}$ are 1.97 and $1.99 \AA$ for $\mathrm{Pt}_{4} / \mathrm{F}_{2} \mathrm{O}$ and $\mathrm{Pt}_{4} / \mathrm{Na}_{2} \mathrm{O}$, respectively. The $\mathrm{Pt}-\mathrm{Pt}$ bond length between the $2 \mathrm{Pt}$ atoms in the cluster that bond to the $\mathrm{CH}_{2}$ decreases from 3.07 to $2.62 \AA$ for $\mathrm{Pt}_{4} / \mathrm{F}_{2} \mathrm{O}$ and $\mathrm{Pt}_{4} / \mathrm{Na}_{2} \mathrm{O}$, respectively.

The other adsorption positions, the 3-fold hollow site and the atop site, are less stable by $50-70 \mathrm{~kJ} / \mathrm{mol}$ (Table 1). If $\mathrm{CH}_{2}$ is initially placed in the 3 -fold site for the $\mathrm{Pt}_{4} / \mathrm{Na}_{2} \mathrm{O}$ cluster, it drifts toward the atop position during the geometry optimization. Due to symmetry restrictions in this calculation (the symmetry is $C_{s}$ ), the $\mathrm{CH}_{2}$ fragment cannot move to the bridged site.

The intrinsic bond energy of $\mathrm{CH}_{2}$ in the bridged position is lower by $13 \mathrm{~kJ} / \mathrm{mol}$ in the case of the acidic $\mathrm{F}_{2} \mathrm{O}$ support ( -605 $\mathrm{kJ} / \mathrm{mol} \mathrm{vs}-592 \mathrm{~kJ} / \mathrm{mol}$ ). This is the reverse order to that found for the adsorption of $\mathrm{H}$ and $\mathrm{CH}_{3}$, which were adsorbed more strongly on the basic supported $\mathrm{Pt}_{4}$ cluster. In contrast, the heat of adsorption, which includes the adsorption of 2 hydrogen atoms, is lowest in the case of the basic support $(-105.7 \mathrm{~kJ} /$ mol compared to $-49.6 \mathrm{~kJ} / \mathrm{mol}$ ).

Figure 6 shows the GPDOS for the $\mathrm{CH}_{2}$ adsorbed on a $\mathrm{Pt}_{4} /$ $\mathrm{F}_{2} \mathrm{O}$ cluster in the bridged position. The results for the $\mathrm{Pt}_{4} / \mathrm{Na}_{2} \mathrm{O}$ cluster are omitted here because no critical information is 
obtained from these DOS. Only the H 1s, C 2s,p and Pt 5d 6s,p DOS of the Pt atoms attached to the $\mathrm{CH}_{2}$ are shown (Figure 6). At $\sim-13 \mathrm{eV}$ the $\mathrm{C} 2 \mathrm{p}$ and $\mathrm{H} 1 \mathrm{~s}$ DOS show simultaneously a maximum, representing the $\mathrm{C}-\mathrm{H}$ bond. The $\mathrm{Pt}$ states peak at a little higher energy, indicating that the mixing between the $\mathrm{C}-\mathrm{H}$ bond and Pt states is limited. At $-12 \mathrm{eV}$, the $\mathrm{C} 2 \mathrm{~s}$,p states show a second maximum in the DOS, this is essentially the $\mathrm{Pt}-\mathrm{C}$ bond. The Pt 5d and 6s,p DOS for both the surface and the interface atoms peak at the same position. Compared to $\mathrm{CH}_{3}$ adsorption (Figure 5), the relative intensity of the Pt 6s,p states is decreased significantly in the primary $\mathrm{Pt}-\mathrm{C}$ bond orbital. Just above the Fermi level at $-6 \mathrm{eV}$, the $\mathrm{C} 2 \mathrm{p}$ and Pt $6 \mathrm{~s}, \mathrm{p}$ states reveal an antibonding state. Note the large $\mathrm{Pt}_{\text {surf }} 6 \mathrm{~s}, \mathrm{p}$ contribution in this antibonding orbital compared to the atop $\mathrm{CH}_{3}$ case, reflecting the decreased importance of $6 \mathrm{sp}$ bonding in the bridged $\mathrm{CH}_{2}$ case.

\section{Discussion}

Hydrogen Adsorption. The $\mathrm{Pt}-\mathrm{H}$ bond lengths with $\mathrm{H}$ in the atop position (1.56 and $1.59 \AA$ for the $\mathrm{F}_{2} \mathrm{O}$ and $\mathrm{Na}_{2} \mathrm{O}$ supports, respectively) are in good agreement with the value of $1.57 \AA$ reported by Papoian et al. ${ }^{28}$ The $\mathrm{Pt}-\mathrm{Pt}$ bond lengths, which are between 2.49 and $2.59 \AA$, are low compared to the bulk value of $2.77 \AA$. However, it is well-known that due to the increasing dehybridization of the Pt valence orbitals for decreasing $\mathrm{Pt}$ particle sizes the $\mathrm{Pt}-\mathrm{Pt}$ bond strength increases and consequently the $\mathrm{Pt}-\mathrm{Pt}$ coordination distance decreases for small clusters. ${ }^{20,36}$ Thus, our calculations clearly reproduce the geometries that have been found in the literature. In general, the favored adsorption position for hydrogen on flat $\operatorname{Pt}(111)$ surfaces is the 3-fold site. ${ }^{28,37}$ However, for small clusters the first hydrogen that adsorbs is known to go into the atop position. ${ }^{20,22}$

The adsorption energies that are found $(-100$ to $-170 \mathrm{~kJ} /$ $\left(\mathrm{mol} \mathrm{H}_{2}\right)$ ) for $\mathrm{H}$ adsorption here are larger than is generally found for $\mathrm{H} / \mathrm{Pt}(111)(-35 \pm 20 \mathrm{~kJ} / \mathrm{mol}){ }^{23,28,34}$ The much higher adsorption energy for hydrogen on the small model cluster compared to adsorption on $\mathrm{Pt}(111)$ surfaces no doubt arises from the low $\mathrm{Pt}-\mathrm{Pt}$ coordination at such sharp cluster corners where the $\mathrm{H}$ is bonded. It also generally agrees with temperature programmed desorption studies that show that all hydrogen desorbs below $300-350 \mathrm{~K}$ from $\mathrm{Pt}(111)$ surfaces $^{38-40}$ whereas hydrogen remains on the surface up to $450 \mathrm{~K}$ for stepped edges $^{38,41,42}$ or on highly dispersed particles..$^{25,43}$

The origin of the large difference in the adsorption energy for basic and acidic supports lies in the relatively large contribution of $\mathrm{Pt}$ 6s, $\mathrm{p}$ states to $\mathrm{Pt}-\mathrm{H}$ bonding, as indicated already in the Introduction. As can be seen in the DOS for the $\mathrm{Pt}_{4} / \mathrm{F}_{2} \mathrm{O}$ cluster (Figure 3 ), the maxima of the $\mathrm{H} 1 \mathrm{~s}$ DOS align to a large extent with the $\mathrm{Pt} 6 \mathrm{~s}, \mathrm{p}$ peaks. This suggests that the bonding of hydrogen to $\mathrm{Pt}$ via the $\mathrm{Pt} 6 \mathrm{~s}, \mathrm{p}$ states is very significant. This has also been reported previously in the literature. Kua and Goddard ${ }^{20}$ performed generalized valence bond (GVB) calculations on a series of Pt clusters of variable size and showed that hydrogen binds in part via the so-called "interstitial bonding orbital" (IBO). When bulk Pt is involved, $\mathrm{Pt}$ atoms share one IBO in each tetrahedron. In fact, this IBO is the bonding combination of the $\mathrm{Pt} 6 \mathrm{~s}$ and $6 \mathrm{p}$ orbitals in $\mathrm{at}_{4}$ tetrahedron. Although others do not use the IBO terminology, it is generally found that the Pt 6s,p states play a significant role in the bonding of $\mathrm{H}$ on $\mathrm{Pt}^{28}$ The specific symmetry properties of the $\mathrm{Pt} 6 \mathrm{~s}, \mathrm{p}$ orbitals are very beneficial for $\mathrm{Pt}-\mathrm{H}$ bonding.

In an earlier paper, it was shown that the location of the IBO within the Pt particle shifts from the metal-support interface

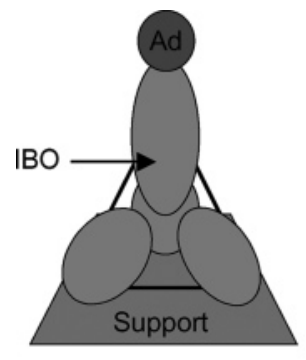

Ionic (basic)

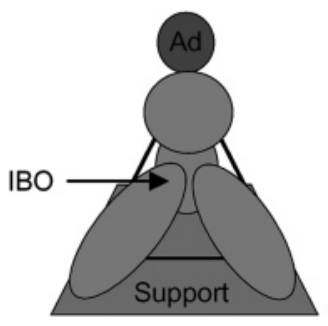

Covalent (Acidic)
Figure 7. Schematic illustration of the interstitial bond orbital (IBO) inside a tetrahedral $\mathrm{Pt}_{4}$ cluster on a ionic (basic) and covalent (acidic) support, with one $\mathrm{H}$ atom adsorbed in an atop position.

to the Pt surface with increasing electron richness of the support oxygen atoms (more basic support). ${ }^{18}$ In addition, some antibonding $6 \mathrm{~s}, \mathrm{p}$ states are shifted below the Fermi level and become populated at the cost of the $\mathrm{Pt} 5 \mathrm{~d}$. This can also be seen when the $\mathrm{H}$ DOS on $\mathrm{Pt}_{4} / \mathrm{F}_{2} \mathrm{O}$ (Figure 3) and $\mathrm{Pt}_{4} / \mathrm{Na}_{2} \mathrm{O}$ (Figure 4) are compared. There are clearly more Pt 6s,p states below the Fermi level for $\mathrm{Na}_{2} \mathrm{O}$, and they are at lower energy relative to the Fermi level. These 6s,p states overlap strongly with the $\mathrm{H} 1 \mathrm{~s}$ orbital. Effectively, with increasing electron richness, the $\mathrm{Pt}$ valence band rehybridizes and obtains more $6 \mathrm{~s}, \mathrm{p}$ character, e.g., from $5 \mathrm{~d}^{9} 6 \mathrm{~s}^{1}$ to $5 \mathrm{~d}^{8.8} 6 \mathrm{~s}^{1.2}$.

These results show that the changes in the $\mathrm{Pt}-\mathrm{H}$ bond strength are correlated with changes in the Pt $6 \mathrm{~s}, \mathrm{p}$ states. When the IBO moves toward the metal-support interface, as is the case for the acidic support, ${ }^{18}$ it can no longer participate in the $\mathrm{Pt}-\mathrm{H}$ bond. The IBO is located below the $5 \mathrm{~d}$ band at $-15 \mathrm{eV}$ in the $\mathrm{Pt}_{4} / \mathrm{F}_{2} \mathrm{O}$ cluster, and at that energy the $\mathrm{H} 1 \mathrm{~s}$ DOS shows no intensity, revealing a lack of bonding between the hydrogen and the IBO. However, on the $\mathrm{Na}_{2} \mathrm{O}$ support, the IBO is located at the surface. ${ }^{18}$ Therefore, the IBO can participate in the $\mathrm{Pt}-\mathrm{H}$ bond and this is indeed shown in Figure 4 for the $\mathrm{H}$ and $\mathrm{Pt}_{\text {surface }}$ DOS of $\mathrm{Pt}_{4} / \mathrm{Na}_{2} \mathrm{O}$. In this cluster, the IBO is located at $-9 \mathrm{eV}$, and the $\mathrm{H} 1$ s orbital shows a small peak at this energy. Because sp states are mixed with the $5 \mathrm{~d}$ band to a greater extent on the basic $\mathrm{Na}_{2} \mathrm{O}$ support, the altered symmetry of the $5 \mathrm{~d}-6 \mathrm{~s}, \mathrm{p}$ orbital (they become more sp like) improves the overlap with $\mathrm{H} 1 \mathrm{~s}$, and consequently, the $\mathrm{Pt}-\mathrm{H}$ bond is strengthened.

Figure 7 illustrates the nature of the IBO and how this changes with the acidity of the support on the basis of the ADF results in Figures 3 and 4. Here the IBO is sketched as a combination of Pt 6s,p orbitals overlapping at the center of the tetrahedron. The more Pt $6 \mathrm{p}$ character, the more we elongate the orbital on the Pt. Thus on the basic support, the $\mathrm{Pt}_{\text {surf }} 6 \mathrm{~s}, \mathrm{p}$ contribution is significantly elongated, showing a strong overlap with the adsorbate, whereas on the acidic support, the $\mathrm{Pt}_{\text {int }} 6 \mathrm{~s}, \mathrm{p}$ contributions are elongated, showing strong overlap with the support $\mathrm{O}$ atoms. Figure 3 (although not showing the DOS on the $\mathrm{Pt}_{\text {int }}$ atoms) does show small $\mathrm{Pt}_{\text {surf }} 6 \mathrm{p}$ DOS just below the Fermi level. This arises because of mixing of the $\mathrm{Pt}_{\text {surf }}$ and $\mathrm{Pt}_{\text {int }}$ orbitals, and the $\mathrm{P}_{\text {int }}$ orbitals are mixing with the $\mathrm{O}$ nonbonding orbitials on the support $\mathrm{O}$ atoms. Overall, a shifting of the IBO from the surface to the interface occurs with increasing acidity, as illustrated in Figure 7. Because the $\mathrm{Pt}_{\text {surf }}-\mathrm{H}$ bond has a strong Pt 6s,p component, this shift significantly affects the $\mathrm{Pt}-\mathrm{H}$ bond strength.

The shift of the s,p states toward the interface with the acidic cluster can also explain the remarkable difference in the geometry of the $\mathrm{H}$ in the atop position in the $\mathrm{Pt}_{4} / \mathrm{Na}_{2} \mathrm{O}$ and $\mathrm{Pt}_{4} /$ $\mathrm{F}_{2} \mathrm{O}$ cluster. $\mathrm{H}$ is tilted much more toward the interface region 
in the case of the acidic $\mathrm{F}_{2} \mathrm{O}$ support (Figure 2). Because the $\mathrm{Pt}$ $6 s, \mathrm{p}$ states are very important in the $\mathrm{Pt}-\mathrm{H}$ bonding, the hydrogen atom tries to "follow" the metal sp states. Therefore, the Pt 6s,p states not only determine the $\mathrm{Pt}-\mathrm{H}$ bond energy but also influence the geometry.

The DFT calculations indicate a preference for the atop site at low coverage, especially on these small clusters. So far, atop $\mathrm{H}$ has never been seen spectroscopically on Pt, except at very high coverage in an electrochemical cell ${ }^{39}$ and on Pt black at low temperatures, ${ }^{17}$ but never at temperatures greater than 330 K. Although atop $H$ has been seen via HREELS on $\operatorname{Ir}(111)$, it has not been seen on $\operatorname{Pt}(111)$ at any coverage or temperature. However, Kua and Goddard ${ }^{42}$ have suggested that at very low coverage (below 1/7 monolayer [ML]) $\mathrm{H}$ may in fact prefer the atop sites on $\operatorname{Pt}(111)$, because it can then maximize its overlap with three interstitial bond orbitals (IBO), although recent ADF results reported by Koper and van Santen ${ }^{48}$ do not find this. At coverage above this level, the $\mathrm{H}$ clearly prefers the 3 -fold fcc sites on $\mathrm{Pt}(111)$, where it can maximize its overlap with one IBO, and not have to share with other $\mathrm{H}$. Recently, ${ }^{22}$ however, atop hydrogen has been observed for small $(D<1 \mathrm{~nm}) \mathrm{Pt}$ particles dispersed on covalent (acidic) supports. Further, ADF results $^{22}$ show that when two or three $\mathrm{H}$ atoms are placed on the simple $\mathrm{Pt}_{4}$ cluster considered here, the $\mathrm{H}$ atoms indeed move to the bridged and 3-fold sites, respectively. Thus the preferred adsorption site depends strongly on the $\mathrm{H}$ coverage, and the ADF results reported here are not necessarily inconsistent with previously reported theoretical or experimental results.

A point about the zero point energies needs to be made here. The total energy of a cluster was determined relative to the atomic reference energies according to Baerends et al. ${ }^{35}$ and the calculations performed were in the spin-restricted mode. A classic example of what can occur in this approximation will become clear from the following. From eqs 1 and 3 , the difference $E_{\mathrm{ads}, \mathrm{H}_{2}}-2 E_{\mathrm{int}, \mathrm{H}}$ equals $-E_{\mathrm{H}_{2}}+2 E_{\mathrm{H}}$ with the dissociation energy of the $\mathrm{H}_{2}$ molecule around $440 \mathrm{~kJ} / \mathrm{mol}$. ${ }^{44}$ However, the results in Table 1 give this energy difference to be approximately $645 \mathrm{~kJ} / \mathrm{mol}$. At equilibrium distance, $\mathrm{H}_{2}$ is reasonably well approximated in the spin-restricted mode because of the closed shell system, but at the dissociation limit the spin-restricted approximation gives an energy for two separated $\mathrm{H}$ atoms that is much too high because of the large ionic components $\left(\mathrm{H}^{+} \mathrm{H}^{-}\right)$forced in this approximation for two separated $\mathrm{H}$ atoms. ${ }^{45}$ Thus the $E_{\text {ads }}$ energies are generally more reliable for comparison with experimental and non-spinrestricted calculations, but both the relative $E_{\text {ads }}$ and $E_{\text {int }}$ energies are reliable for determining the preferred binding sites.

$\mathbf{C H}_{3}$ Adsorption. The optimized geometries for $\mathrm{CH}_{3}$ adsorbed in the atop site show features similar to those of the $\mathrm{H}$ adsorbed in the atop position. The $\mathrm{Pt}-\mathrm{C}$ bond lengths of 2.03 (acidic cluster) and $2.09 \AA$ (basic) are similar to values reported in the literature..$^{26-28}$ The favored atop adsorption position is also well-known for the adsorption of $\mathrm{CH}_{3}$ fragments. $\mathrm{CH}_{n}$ fragments generally tend to maintain the tetrahedral geometry; i.e., $\mathrm{CH}_{3}$ adsorbs in an atop position, $\mathrm{CH}_{2}$ in the bridged position, and $\mathrm{CH}$ in the 3 -fold hollow site. ${ }^{26-28,46}$

We find intrinsic bond energies $E_{\text {int }}$ for adsorption of $\mathrm{CH}_{3}$ and $\mathrm{H}$ of $-304 \mathrm{~kJ} / \mathrm{mol}\left(\mathrm{F}_{2} \mathrm{O}\right.$ support) to $-320 \mathrm{~kJ} / \mathrm{mol}\left(\mathrm{Na}_{2} \mathrm{O}\right)$. This is larger than the values reported in the literature $(-200$ $\mathrm{kJ} / \mathrm{mol}^{46}$ ) for $\mathrm{CH}_{3}$ adsorption on $\mathrm{Pt}(111)$ surfaces. This difference is caused again by the coordinatively unsaturated nature of the Pt atoms in a Pt cluster compared to a flat (111) surface. In addition, the calculations reported here do not fully account for the spin properties, and therefore the true atomic ground state and true bond energy are not calculated. The trends that are observed, however, are not spin-related and can be calculated reliably without using the computationally expensive calculations including spin-orbit effects. Although $E_{\text {int }}$ is only lower by $16 \mathrm{~kJ} / \mathrm{mol}$ for the basic support, the heat of adsorption $E_{\text {ads }}$ is lower by $50 \mathrm{~kJ} / \mathrm{mol}$. This large drop in $E_{\text {ads }}$ reflects the much larger change $(35 \mathrm{~kJ} / \mathrm{mol})$ in $\mathrm{Pt}-\mathrm{H}$ bond strength going from acidic to basic supports.

When the DOS for $\mathrm{CH}_{3}$ vs $\mathrm{H}$ adsorbed on $\mathrm{Pt}_{4} / \mathrm{F}_{2} \mathrm{O}$ (Figures 5 and 3) are compared, some interesting differences are seen. The C 2 p states show some overlap with the Pt 6s,p states, but the degree of overlap is much smaller for $\mathrm{Pt}-\mathrm{CH}_{3}$ than for $\mathrm{Pt}-$ $\mathrm{H}$. However, the $\mathrm{Pt}-\mathrm{CH}_{3}$ bond involves more $\mathrm{Pt} 5 \mathrm{~d}$ states than the $\mathrm{Pt}-\mathrm{H}$ bond. This means that the $\mathrm{Pt} 6 \mathrm{~s}, \mathrm{p}$ states are more important for the $\mathrm{Pt}-\mathrm{H}$ bonding and that the $\mathrm{Pt} 5 \mathrm{~d}$ states are more essential for the chemisorption of $\mathrm{CH}_{3}$ on $\mathrm{Pt}$.

The Pt 6 s and $6 \mathrm{p}$ orbitals are very diffuse, whereas the Pt 5d orbitals are more localized with specific geometries. Due to their delocalized nature, the Pt 6s,p states have more interaction with the support and consequently are less affected than the localized Pt $5 d$ states. Because the Pt $6 \mathrm{~s}$ and p states are more important for chemisorption of $\mathrm{H}$ than for $\mathrm{CH}_{3}$, it can be concluded that the influence of the support is less important for the chemisorption of $\mathrm{CH}_{3}$.

$\mathbf{C H}_{2}$ Adsorption. As expected, $\mathrm{CH}_{2}$ preferentially adsorbs in the bridged position where it can complete the carbon's tetrahedral geometry (Figure 2E,F). The $\mathrm{Pt}-\mathrm{C}$ bond length of $\sim 2.00 \AA$ is in agreement with the work of Kua and Goddard, ${ }^{26,27}$ but it is much smaller than the $2.3 \AA$ reported by $\mathrm{Paul}^{46}$ for the adsorption of $\mathrm{CH}_{2}$ in the bridged position on $\mathrm{Pd}$ (111). In the case of the $\mathrm{Pt}_{4} / \mathrm{F}_{2} \mathrm{O}$ cluster, the adsorption of $\mathrm{CH}_{2}$ leads to a large elongation of the $\mathrm{Pt}-\mathrm{Pt}$ bond length to $3.07 \AA$ between the $\mathrm{Pt}$ atoms forming the bridge. This elongation suggests that the $\mathrm{CH}_{2}$ is adsorbed very strongly, because it weakens the $\mathrm{Pt}-\mathrm{Pt}$ bond to a large extent. This elongation is not observed for the $\mathrm{Pt}_{4} / \mathrm{Na}_{2} \mathrm{O}$ cluster. In agreement with these observations, the intrinsic bond energy $E_{\text {int }}$ is more negative (more exothermic) by $13 \mathrm{~kJ} / \mathrm{mol}$ for the $\mathrm{Pt}_{4} / \mathrm{F}_{2} \mathrm{O}$ cluster compared to the $\mathrm{Pt}_{4} / \mathrm{Na}_{2} \mathrm{O}$ cluster. However, the heat of adsorption $E_{\text {ads }}$ is more negative in the case of the $\mathrm{Na}_{2} \mathrm{O}$ support. This again is caused by the larger difference in the $\mathrm{Pt}-\mathrm{H}$ bond strength, because during the dissociative adsorption of $\mathrm{CH}_{4}$ as $\mathrm{CH}_{2}, \mathrm{CH}_{4} \rightarrow \mathrm{CH}_{2}+2 \mathrm{H}$, two hydrogen atoms are adsorbed on the $\mathrm{Pt}_{4}$ cluster. This means that the dissociative adsorption of $\mathrm{CH}_{4}$ is more exothermic for adsorption on the $\mathrm{Pt}_{4} / \mathrm{Na}_{2} \mathrm{O}$ cluster than it is on the $\mathrm{Pt}_{4} / \mathrm{F}_{2} \mathrm{O}$ cluster, although the intrinsic $\mathrm{Pt}-\mathrm{CH}_{2}$ bond strengths are in the reverse order. Clearly, the change in the $\mathrm{CH}_{2}$ heat of adsorption is governed by the hydrogen intrinsic adsorption energy.

From a comparison of the DOS of $\mathrm{CH}_{2}$ in the bridged position (Figure 6) with the DOS of $\mathrm{CH}_{3}$ on the atop position (Figure 5) on the $\mathrm{Pt}_{4} / \mathrm{F}_{2} \mathrm{O}$ cluster, it is clear that the $\mathrm{CH}_{2}$ adsorption involves even less $\mathrm{Pt} 6 \mathrm{~s}, \mathrm{p}$ states and more $\mathrm{Pt} 5 \mathrm{~d}$ states than the $\mathrm{CH}_{3}$. Therefore, the adsorption of $\mathrm{CH}_{2}$ is mainly determined by the influence of the support acidity on the d-band. On acidic supports, the d-band is shifted to lower energies, which is beneficial for the overlap of the $\mathrm{C} 2 \mathrm{p}$ and $\mathrm{Pt} 5 \mathrm{~d}$ band when $\mathrm{CH}_{2}$ is adsorbed.

The importance of the Pt $5 \mathrm{~d}$ states for the bonding of $\mathrm{CH}_{x}$ fragments is in agreement with results reported by Nørskov et al. ${ }^{47}$ They show that the adsorption energy correlates with the energy of the d-band center across a transition metal series. The diffuse metal sp states effectively are the same across a transition 


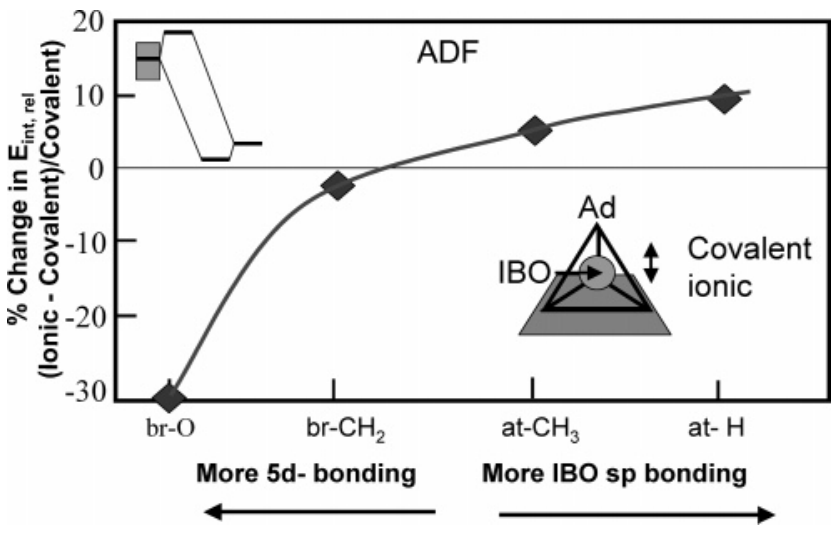

Figure 8. Relative intrinsic bond energy as a function of the type of $\mathrm{Pt}$-adsorbate bonding with the covalent (acid)/ionic (basic) properties of the support as independent parameter. The average $E_{\text {int }}$ is set to zero for each adsorbate. The $\mathrm{Pt}[\mathrm{sp} /(\mathrm{sp}+\mathrm{d})]$ ratio determines the support effect.

metal series, and only changes in the d-band are reflected in the adsorption energies.

Oxygen Adsorption. As shown in work previously reported, ${ }^{23}$ the Pt 6s,p orbitals are much less significant in the $\mathrm{Pt}-\mathrm{O}$ bonding compared with $\mathrm{Pt}-\mathrm{H}$, so the IBO rearrangement is not primarily responsible for the change in $\mathrm{Pt}-\mathrm{O}$ bonding with support acidity in this case. Indeed the DFT results in Table 1 confirm that the $\mathrm{Pt}-\mathrm{O}$ bond strength increases on the acidic $\mathrm{O} / \mathrm{Pt}_{4}\left(\mathrm{~F}_{2} \mathrm{O}\right)_{3}$ cluster compared with the basic cluster $\mathrm{O} / \mathrm{Pt}_{4}$ $\left(\mathrm{Na}_{2} \mathrm{O}\right)_{3}$ (an increase of nearly $30 \%$ compared with a less than $10 \%$ decrease for $\mathrm{Pt}-\mathrm{H}$; see Table 1). The Figure 8 insert schematically illustrates the decrease in ionic character (increase in covalent character and hence bond strength) of a $\mathrm{Pt}-\mathrm{O}$ bond with increasing $\mathrm{Pt} 5 \mathrm{~d}$ valence band shift to higher binding energy. This schematic is appropriate for a transition metal, an example of the adsorbate/metal bonding in the "two-level" strong adsorption limit. ${ }^{48}$

Influence of the Support Acid/base Properties on the Adsorbate Bonding. When the DOS for adsorption of $\mathrm{H}, \mathrm{CH}_{3}$, and $\mathrm{CH}_{2}$ in their optimal positions are compared, the importance of the $\mathrm{Pt} 6 \mathrm{~s}, \mathrm{p}$ states in the bonding increases in the order $\mathrm{O}<$ $\mathrm{CH}_{2}<\mathrm{CH}_{3}<\mathrm{H}$. The high importance of the metal d orbitals in the $\mathrm{M}-\mathrm{CH}_{n}$ bond with highly unsaturated $\mathrm{C}$ atoms (e.g., $n$ $=0$ ) was observed earlier ${ }^{46}$ and as discussed above, the predominance of $\mathrm{Pd} \mathrm{d}$ orbital bonding with $\mathrm{O}$ is also wellknown. The influence of the support acid/base properties on adsorbate bonding appears to be the largest when the adosrbate bonding is dominated by either the $\mathrm{Pt} 5 \mathrm{~d}$ or $\mathrm{Pt} 6 \mathrm{~s}, \mathrm{p}$. The calculations involving $\mathrm{CH}_{2}$ and $\mathrm{CH}_{3}$ adsorbed on $\mathrm{Pt}_{4}\left(\mathrm{X}_{2} \mathrm{O}\right)_{3}$ clusters showed relatively small differences in the bonding with a change in $\mathrm{X}$, even though the $\mathrm{CH}_{x}$ fragments also have a strong bonding component with the Pt d orbitals. Indeed the trend in the $\mathrm{Pt}-\mathrm{C}$ bond strength is in the opposite direction for the atop $\mathrm{CH}_{3}$ (decrease in $\mathrm{Pt}-\mathrm{C}$ bonding) versus the bridged $\mathrm{CH}_{2}$ (increase in $\mathrm{Pt}-\mathrm{C}$ bonding) fragment with support acidity. It seems clear that the $\mathrm{CH}_{x}$ fragments have significant components of both $5 \mathrm{~d}$ and $6 \mathrm{~s}, \mathrm{p}$, and the opposite effects of the $5 \mathrm{~d}$ valence band shift and 6sp IBO rearrangement on the bonding cancel each other nearly out. The Pt $6 \mathrm{~s}, \mathrm{p} / \mathrm{Pt} 5 \mathrm{~d}$ bonding ratio apparently increases in the order $\mathrm{O}$ (br) $<\mathrm{CH}_{2}$ (br) $<\mathrm{CH}_{3}$ (atop) $<\mathrm{H}$ (atop). Figure 8 shows the change in $E_{\text {int }}$ (acid-base/base) relative to that in the acidic support for each of the adsorbates. Further, the relative importance of the $\mathrm{Pt} 5 \mathrm{~d}$ vs $\mathrm{Pt} 6 \mathrm{~s}, \mathrm{p}$ bonding is schematically indicated.

Implications for Catalysis. Figure 8 clearly shows that the support has the most dramatic effect on the $\mathrm{H}$ and $\mathrm{O}$ adsorption compared to $\mathrm{CH}_{2}$ and $\mathrm{CH}_{3}$. This has significant implications for catalysis. It suggests that when changes are seen in the turnover frequency with support ionicity, these changes may result more from changes in the $\mathrm{H}$ or $\mathrm{O}$ coverage, than from changes in the bond strength of the $\mathrm{Pt}$-hydrocarbon.

As mentioned in the Introduction above, in the conversion of neopentane $\left(\mathrm{C}-\left(\mathrm{CH}_{3}\right)_{4}\right)$, it has been observed that the rate of hydrogenolysis is several orders of magnitude higher when Pt particles are supported on an acidic support compared to a basic support. A detailed analysis of the kinetic data for neopentane hydrogenolysis as reported by us ${ }^{10}$ recently showed that the $\mathrm{H}$ coverage directly affected the neopentane-Pt bond strength through the Frumkin isotherm and thereby changed the activation energy for the reaction. Preliminary results for the hydrogenation of benzene and other alkenes catalyzed by Pt on supports with different ionicities show that the change in $\mathrm{H}$ coverage may be the most responsible for the observed change in reactivity.

The decreasing bond strength of the $\mathrm{Pt}-\mathrm{O}$ bond with ionicity of the support can also have significant implications for reactions involving $\mathrm{O}$. In the direct methanol fuel cell, $\mathrm{CO}$ poisoning of the Pt surface is a severe problem. ${ }^{49} \mathrm{Pt}$ is often alloyed with another metal such as Ru, to lower the potential for the onset of $\mathrm{OH}$ formation from the water. This $\mathrm{OH}$, in the bifunctional mechanism is believed to react with the $\mathrm{CO}$, producing $\mathrm{CO}_{2}$, which then leaves the surface. ${ }^{50,51}$ These results suggest that it is worthwhile to consider changing the support from the usual amorphous carbon at the cathode of the fuel cell. A highly covalent (acidic) support, which according to the results above should decrease the potential for the onset of $\mathrm{OH}$ and $\mathrm{O}$ formation, should lower the potential when the $\mathrm{CO}$ oxidation reaction occurs. This would significantly decrease the $\mathrm{CO}$ poisoning and thereby increase the efficiency of the methanol oxidation.

\section{Conclusions}

DFT results for $\mathrm{CH}_{x}$ on small supported Pt clusters, along with those reported previously for $\mathrm{O}$ and $\mathrm{H}$, show that the importance of the $\mathrm{Pt} 6 \mathrm{~s}, \mathrm{p}$ states in the chemisorption bond increases in the order $\mathrm{O}<\mathrm{CH}_{2}<\mathrm{CH}_{3}<\mathrm{H}$. The Pt $5 \mathrm{~d}$ and $6 \mathrm{~s}, \mathrm{p}$ states are influenced strongly by the support acid/base properties, thereby influencing the bonding of the adsorbates. On covalent (acidic) supports, the sp states are moved toward the metal-support interface, and consequently, the adsorbate bond energies are decreased for $\mathrm{CH}_{3}$ and $\mathrm{H}$, when $\mathrm{Pt} 6 \mathrm{~s}, \mathrm{p}$ bonding dominates. However, on ionic (basic) supports the $\mathrm{Pt}$ 6s,p states are located at the surface of the Pt cluster and are readily available for the bonding to adsorbates. In contrast, the $\mathrm{Pt} 5 \mathrm{~d}$ orbitals dominate for $\mathrm{Pt}-\mathrm{CH}_{2}$ and $\mathrm{O}$ adsorbate bonding. In this case the $\mathrm{Pt}$-adsorbate bond is stronger for acidic supports than for basic supports.

These results have significant implications for catalysis. They have already been used to explain the compensation effect and the negative order in the partial pressure of hydrogen found for the hydrogenolysis of neopentane catalyzed by supported $\mathrm{Pt}$ particles ${ }^{10}$ and have potential for use in designing improved catalysts in the direct methanol fuel cell.

\section{References and Notes}

(1) Gates, B. C. Chem. Rev. 1995, 95, 511-522.

(2) Dalla Betta, R. A., Boudart, M. Proc. 5th Int. Congr. Catal. 1973, 1329-1341.

(3) Homeyer, S. T.; Karpinski, Z.; Sachtler, W. M. H. J. Catal. 1990, $123,60-73$. 

538.

(4) de Mallmann, A.; Barthomeuf, D. J. Chim. Phys. 1990, 87, 535-

(5) Karpinski, Z.; Gandhi, S. N.; Sachtler, W. M. H. J. Catal. 1993, $141,337-346$.

(6) Xu, Z.; Xiao, F. S.; Purnell, S. K.; Alexeev, O.; Kawi, S.; Deutsch, S. E.; Gates, B. C. Nature 1994, 372, 346-348.

(7) Reyes, P.; Concha, I.; König, M. E.; Fierro, J. L. G. Appl. Catal. A 1993, 103, 5-16.

(8) Mojet, B. L.; Miller, J. T.; Ramaker, D. E.; Koningsberger, D. C. J. Catal. 1999, 186, 373.

(9) Koningsberger, D. C.; de Graaf, J.; Mojet, B. L.; Ramaker, D. E.; Miller, J. T. Appl. Catal. A 2000, 191, 205.

(10) Koningsberger, D. C.; Oudenhuijzen, M. K.; de Graaf, J.; van

Bokhoven, J. A.; Ramaker, D. E. J. Catalysis 2003, 216, 178.

(11) Bond, G. C. Catal. Today 1993, 17, 399.

(12) Gault, F. G. Adv. Catal. 1981, 30.

(13) Foger, K.; Anderson, J. R. J. Catal. 1978, 54, 318-335. $3-22$

(15) Larsen, G.; Haller, G. L. Catal. Lett. 1989, 3, 103-110. 9037.

(16) Ferrari, A. M.; Pacchioni, G. J. Phys. Chem. 1996, 100, 9032-

(17) Jansen, A. P. J.; van Santen, R. A. J. Chem. Phys. 1990, 94, 6764.

(18) Ramaker, D. E.; de Graaf, J.; van Veen, J. A. R.; Koningsberger,

D. C. J. Catal. 2001, 203, 7.

(19) López, N. J. Chem. Phys. 2001, 114, 2355-2361.

(21) Ramaker, D. E.; Oudenhuijzen, M. K.; Koningsberger, D. C. Phys. Rev. B, submitted.

(22) Oudenhuijzen, M. K.; van Bokhoven, J. A.; Miller, J. T.; Ramaker, D. E.; Koningsberger, D. C. J. Am. Chem. Soc., in press, 2004.

(23) Ramaker, D. E.; Teliska, M.; Zhang, Y.; Stakheev, A. Yu.; Koningsberger, D. C. Phys. Chem. Chem. Phys. 2003, 5, 4492-4501.

(24) Teliska, M.; O'Grady, W. E.; Ramaker, D. E. J. Phys. Chem. B 2004, 108, 2333.

(25) Teliska, M.; O’Grady, W. E.; Ramaker, D. E. To be submitted.

(26) Kua, J.; Faglioni, F.; Goddard, W. A., III. J. Am. Chem. Soc. 2000 122, 2309-2321.

(27) Kua, J.; Goddard, W. A., III. J. Phys. Chem. B 1998, 102, 94929500
(28) Papoian, G.; Nørskov, J. K.; Hoffmann, R. J. Am. Chem. Soc. 2000, $122,4129-4144$

(29) Amsterdam Density Functional Package ADF 2000.02, Department of Theoretical Chemistry, Vrije Universiteit, Amsterdam. http:// www.scm.com.

(30) Becke, A. D. J. Chem. Phys. 1986, 85, 7184-7187.

(31) Perdew, J. P. Phys. Rev. B 1986, 33, 8822-8824.

(32) Philipsen, P. H. T.; van Lenthe, E.; Snijders, J. G.; Baerends, E. J. Phys. Rev. B 1997, 56, 13556.

(33) van Lenthe, E.; Baerends, E. J.; Snijders, J. G. J. Chem. Phys. 1994 101,9783

(34) Olsen, R. A.; Kroes, G. J.; Baerends, E. J. J. Chem. Phys. 1999, $111,11155-11163$

(35) Baerends, E. J.; Branchadell, V.; Sodupe, M. Chem. Phys. Lett, 1997, 265, 481-489.

(36) Yang, L.; DePristo, A. E. J. Catal. 1994, 149, 223-228.

(37) Renouprez, A.; Jobic, H. J. Catal. 1988, 113, 509-516.

(38) Davis, S. M.; Somorjai, G. A. Surf. Sci. 1980, 91, 73-91.

(39) Ko, C. S.; Gorte, R. J. Surf. Sci. 1985, 161, 597-607.

(40) Christmann, K.; Ertl, G. Surf. Sci., 1976, 60, 365-384.

(41) Wang, H.; Tobin, R. G.; Lambert, D. K.; Fisher, G. B.; Dimaggio, C. L. Surf. Sci. 1995, 330, 173-181.

(42) Wang, H.; Tobin, R. G.; Lambert, D. K. J. Chem. Phys. 1994, 101, 4277-4285

(43) Tsuchiya, S.; Amenomiya, Y.; Cvetanovic, R. J. J. Catal. 1970, 19, 245-255.

(44) Atkins, P. W. Physical Chemistry; W. H. Freeman: New York, $1986 ;$ p 817.

(45) Perry, J. K.; Tahir-Kheli, J.; Goddard, W. A., III. Phys. Rev. B 2001, 63, 144510.

(46) Paul, J. F.; Sautet, P. J. Phys. Chem. B 1998, 102, 1578-1585.

(47) Ruban, A.; Hammer, B.; Stoltze, P.; Skriver, H. L.; Nørskov, J. K. J. Mol. Catal. A 1997, 115, 421-429.

(48) Koper, M. T. M.; van Santen, R. A. J. Electroanal. Chem. 1999. 472, 126.

(49) Gasteiger, H. A.; Markovic, N.; Ross, Jr. P. N.; Cairns, E. J. J. Phys. Chem. 1993, 97, 12020.

(50) Rice, C. L. C.; Masel, R. I.; Babu, P. K.; Waszczuk, P.; Kim, H S.; Oldfield, E.; Wieckowski, A. J. Phys. Chem. B 2002, 106, 9581.

(51) Lu, C.; Masel, R. I. J. Phys. Chem. B 2001, 105, 9793. 